\title{
A mídia e o corpo: o que o jovem tem a dizer?
}

\section{The media and the body: what the young people have to say?}

M aria Aparecida Conti ${ }^{1}$

Maria N atacha Toral Bertolin ${ }^{2}$

Stela Verzinhasse Peres ${ }^{3}$

1 Instituto de Psiquiatria da FaculdadedeM edicina, Universidade de São Paulo. Rua Dr. Ouvídio Pires de Campos 785/2ㅇadar, Cerqueira César. 05403010 São Paulo SP. maconti@usp.br

${ }^{2}$ Departamento deN utrição, Universidade de Brasília.

${ }^{3}$ FaculdadedeSaúde

Pública, Universidade de São Paulo.
Abstract The aim of this article is to verify the perception of the young about the relation between themedia, especially the TV and magazine access and the body of the adolescent. I t is a crosssection study carried out with 121 adolescents of a private school in São Paulo. A semi-structured individual interview was applied and recorded in magnetic ribbon using the methodology of the discourse of the collective subject based in the concept of social representation. The data weretabulated using threemethodological approaches: central idea; key expressions and discourse of the collective subjective. The discourses of adolescents were evaluated, indicating that $95 \%$ of central ideas expressed relations among TV, magazines and the body and the most common ideas were about the stimulation of the thinness ideal physicist and the negative influence with hazard experience and illnesses appear. In 5\% of central ideas registered no relation among $T V$, magazines and the body. We could conclude that young people show the knowledge about the intense media's interference in the adolescent body. Key words Adolescence, M edia, Social representation, Qualitative research
Resumo 0 objetivo deste estudo éverificar a percepção do jovem quanto à relação entre a mídia, especialmente 0 acesso à televisão e revistas e 0 corpo do adol escente. Trata-se de um estudo transversal, realizado com 121 adolescentes em uma instituição particular de ensino do ABC paulista. Aplicou-se uma entrevista individual semiestruturada gravada em fita magnética. Estas foram avaliadas utilizando-se a metodologia do discurso do sujeito coletivo, embasada no conceito das re presentações sociais. A tabulação dos dados ocorreu por meio da utilização de três figuras metodológi cas: idéia central, expressões chave e o discurso do sujeito coletivo. $N$ os discursos dos jovens, foram registradas em $95 \%$ das idéias centrais relações entre a TV, revistas e o corpo, sendo as mais frequentes relacionadas ao estímulo a um ideal físico de magreza eà influência negativa com experiências de humilhação e desencadeamento de doenças. Em 5\% das idéias centrais, não se registrou relação entre a TV, revistas e o corpo. Conclui-se que os jovens revelaram conhecimento acerca da intensa interferência da mídia em relação ao corpo do adolescente.

Palavras-chave Adolescência, Mídia, Representação social, Pesquisa qualitativa 
Introdução

A mídia, sinônimo de "meios de comunicação social", diz respeito aos veículos responsáveis pela difusão das informações, como rádio, jornais, revistas, televisão, vídeo, entre outros ${ }^{1}$. Configura-se, na atualidade, como uma das instituições responsáveis pela educação no mundo moderno, trazendo tanto benefícios como malefícios, respondendo pela transmissão de valores e padrões de conduta e social izando muitas gerações².

A adolescência, compreendida como uma construção social moderna, representa uma possibilidade de emergência da subjetividade com novas referências e padrões identitários ${ }^{3}$. Particularmente para os adolescentes, os meios de comunicação contribuem inegavelmenteparaum aprendizado sobre modos de comportar-se, sobre modos de constituir-se a si mesmo4.

A influência da televisão sobre o comportamento do jovem é um fato reconhecido mundialmente. Pesquisa envolvendo jovens italianos revelou que $50 \%$ destes têm um aparelho em seu quarto, os quais são fortemente influenciados pela publicidade na aquisição de produtos, além de demonstrarem em quase sua totalidade $(92,2 \%)$ grande interesse pela televisão ${ }^{5}$. Tigge mann et al. ${ }^{6}$, pesquisando jovens australianos, registraram a forte influência da mídia na construção de um corpo magro.

Para Fisher ${ }^{4}$, esta influência vai além de uma simples fonte básica de lazer, tratando-se de um lugar extremamente poderoso no que tange à produção e à circulação de uma série de valores, concepções, representações relacionadas a um aprendizado cotidiano sobre quem nós somos, o que devemos fazer com o nosso corpo, entre outros. Ainda para a mesma autora, a televisão, em especial, participa diretamente na formação do jovem, sugerindo, estimulando e delineando determinadas formas de existência coletiva ou da relação consigo mesmo e com o outro ${ }^{7}$.

Dos meios de comunicação social, a TV é o mais difundido no Brasil. Segundo a Pesquisa Nacional por Amostra de Domicílios (PNAD) ${ }^{8}$ este aparelho eletrodoméstico está presente em 91,4\% das residências no território nacional, com destaque para a Região Sudeste, que registrou as maiores proporções $(94,4 \%)$.

Além de que, a televisão, com suas programações diárias, preenche lacunas sociais e culturais geradas pela falta de acesso ao teatro, cinema, lazer e informação. Em muitos casos, substitui também a escola, como, por exemplo, nas produções de ensino à distância9. A TV divide ainda com a família o espaço de formação no quese refere às relações identitárias e de identificação afetiva e moral, bem como à transmissão dos conteúdos culturais².

A questão levantada neste estudo é em que medida os jovens estão atentos à participação da televisão em sua formação e escolhas. Para tanto, se objetivou avaliar a percepção dos adolescentes quanto à relação estabel ecida entre a TV e as revistas e o corpo.

\section{Métodos}

Este estudo refere-se a uma etapa da pesquisa de doutoramento da primeira autora, envolvendo jovens do ensino fundamental I e fundamental II, com idades entre dez a dezoito anos. Trata-se de um estudo do tipo transversal, do qual participaram adolescentes regularmentematriculados em uma instituição da rede particular de ensino no $A B C$ paulista.

A amostra selecionada foi intencional ${ }^{10,11}$, correspondendo aos 386 jovens que participaram da etapa citada. Todos foram convidados a participar e aqueles que se disponibilizaram foram entrevistados individualmente. Estes compuseram uma amostra de 121 adolescentes. A participação foi voluntária e a coleta de dados ocorreu em dezembro de 2006 em uma sala restrita disponibilizada pela direção escolar.

Antecedendo o trabal ho de campo, realizouse, em setembro de 2006, um pré-teste com um grupo deadolescentes da mesma instituição, sendo estes, por um critério de disponibilidade de horários, selecionados pela coordenação pedagógica. Totalizaram 28 jovens de ambos os sexos, na faixa etária média de treze anos e, sequencialmente, os ajustes necessários para uma maior compreensão da entrevista foram realizados.

A plicou-se a técnica da entrevista semiestruturada, caracterizada como entrevistas episódicas, que combina em sua estrutura convites para narrar acontecimentos da vida pessoal ${ }^{12}$. As entrevistas foram gravadas em fita magnética, sendo solicitado ao adolescente que respondesse a seguinte pergunta: "Fale um pouco da relação entre a TV e a revista e a forma como o jovem cuida do corpo". A duração das entrevistas variou de três a doze minutos. Posteriormente, as entrevistas foram transcritas.

Paraanálise do conteúdo discursivo, utilizousea técnica deanálise do discurso do sujeito coletivo (DSC), que consiste em utilizar um instrumento detabulação eorganização dos dados qua- 
litativos com a aplicação das figuras metodológicas: "expressões-chave"; ; idéias centrais" e o "discurso do sujeito coletivo" (DSC) ${ }^{13}$. Dessa forma, a partir do material verbal coletado nas entrevistas, constituiu-se um discurso-síntese do grupo.

Esta técnica embasa-se no conceito das repre sentações sociais ${ }^{14}{ }^{14}$ como uma forma de expressar diretamente a representação social de um dado sujeito social ${ }^{15}$. Para a elaboração dos DSC, utilizou-se o programa Qualiquantisoft, versão 1.3C.

0 estudo foi desenvolvido de acordo com a Resolução n 196/96 do Conselho Nacional de Saúde eaprovado pelo ComitêdeÉtica da Faculdade de Saúde Pública da Universidade de São Paulo.

\section{Resultados}

Dos 121 jovens participantes, $63 \%$ eram do sexo feminino. As idades dos adolescentes variaram entre onze e dezoito anos, com a média de idade de 13,8 anos e desvio padrão de 2,1 anos. Cursavam da quinta série (ensino fundamental i) ao terceiro ano colegial (ensino fundamental ii).

Das respostas obtidas, foram extraídas 189 expressões-chave, que foram agrupadas em dezesseis idéias centrais, cujas representações desdobraram-se em quatro eixos, sendo estes: (1) presença de uma relação negativa entre a mídia e o corpo" (64\%); (2) uma relação positiva e uma relação positiva e negativa concomitantemente, entrea mídia eo corpo (18\%); (3) há uma relação, no entanto, sem julgamento de valor (13\%); (4) pouca ou nenhuma relação entre a mídia e o corpo $(5 \%)$. Desta forma, observa-se que a maior frequência dos discursos identificou relação entre a mídia e o corpo do jovem (95\%), em contraponto a $5 \%$ das ideias centrais que não identificaram ou identificaram muito pouco esta relação.

$\mathrm{Na}$ Tabela 1, observam-se as ideias centrais e trechos dos discursos do sujeito coletivo queidentificaram tipos diferentes de relações negativas entrea mídia e o corpo. A idéia central referenteà "cobrança de um ideal físico" registrou a maior frequência entre todas as respostas (25\%).

As ideias centrais e os discursos com representações sociais que identificaram uma relação positiva e uma relação positiva enegativa concomitantemente são apresentadas na Tabela 2. As idéia centrais "existeo lado positivo enegativo" e "a influência é positiva" correspondeu a 9\%, para ambas, respectivamente.

A Tabela 3 apresenta as ideias centrais e tre chos dos discursos do sujeito coletivo queidenti- ficaram relação entre a mídia e o corpo do adolescente, mas sem julgamento de valor, descrevendo o fato em si. A idéia central "existe relação entre a TV e o corpo do jovem", com 9\%, registrou a maior frequência entre todas as respostas.

$\mathrm{Na}$ Tabela 4, registram-se as ideias centrais e os discursos com representações sociais que expressaram os conteúdos que identificaram pouca ou nenhuma relação entre a mídia e o corpo. A ideia central "não influencia" correspondeu a $5 \%$ da frequência entre todas as respostas.

\section{Discussão}

Foi possível verificar a percepção do grupo frente à influência da mídia no cotidiano dos jovens, com maior destaque para a TV. Quase a totalidade das idéias centrais (95\%) inferiu esta relação, principalmente ressaltando o aspecto negativo, pela cobrança deum ideal físico, tanto para meninos como para meninas (25\%), e pelo desencadeamento de doen ças e sentimentos depreciativos, como a humilhação (11\%).

Esta relação foi verificada com meninas australianas na faixa etária de onze a dezesseis anos. Tiggemann et al. ${ }^{6}$ trabalharam com grupo focal, confirmando o quanto as influências socioculturais, em particular a mídia, exercem sobre as jovens para serem magras. As autoras observaram, no discurso das meninas, uma elaborada conceituação acerca da relação entreos efeitos da mídia para a imagem corporal. Sendo assim, as jovens revelaram conhecimento acerca dos possíveis fatores queinfluenciam os adolescentes. Este mesmo efeito foi registrado no presente estudo. Pelo discurso do sujeito coletivo, foi possível confirmar queosjovens estão atentos à interferência da mídia no que se refere ao corpo.

0 ideal físico para meninas na sociedade ocidental contemporâneaéa magreza, fato esteconfirmado por vários pesquisadores ${ }^{16,17}$. Para as jovens australianas, as duas principais razões do desejo em ser magra são baseadas, primeiramente, na influência das modelos e da mídia e, em um segundo momento, para sentirem-se mais atraentes e receberem mais atenção.

Fischer ${ }^{4}$ afirma que os imperativos de beleza, da juventudee da longevidade, sobretudo nos espaços dos diferentes meios de comunicação, perseguem o indivíduo como instrumento de tortura por meio de corpos que são oferecidos como modelos determinando a beleza. Coimbra ${ }^{18}$ sinaliza o poder da mídia como um dos mais importantes equipamentos sociais, no sentido de pro- 
Tabela 1. Ideia central, frequência da resposta e o discurso do sujeito coletivo dos adolescentes, segundo conteúdos que identificaram uma relação negativa entre a mídia e o corpo. São Bernardo do Campo, 2006.

\begin{tabular}{ll}
$\begin{array}{c}\text { Ideia central } \\
\text { (frequência da resposta) }\end{array}$ & \multicolumn{1}{c}{ Trechos do discurso do sujeito coletivo } \\
\hline $\begin{array}{l}\text { Cobrança de um ideal } \\
\text { físico }(25, \%)\end{array}$ & "Tem total influência, porque o que é bonita tá na televisão e a gente quer ser \\
bonita, né? [...] São esses meios que ditam como que o ideal seria você ser e é \\
uma coisa ruim isto [...] Eles colocam um padrão, com cinturinha e o corpo \\
perfeito, escultural, sem celulite, sem nada, sendo que toda mulher tem, né? \\
Todas as meninas quer emagrecer e quer ser igual as modelos e tudo é em volta \\
de ser magro, daí se você é gordo, tá fora, não pode fazer parte da sociedade \\
{$[\ldots] "$.}
\end{tabular}

Estímulo ao desenvolvimento de doenças e sentimento de humilhação (11\%)

Existe mas depende de cada um (8\%)

A TV engana, mostra uma coisa que não é $(5, \%)$

Interfere ditando um padrão de moda (4\%)

Afeta mais as meninas (4\%)

Seguir estereótipos para ser aceito (4\%)

Influencia no comportamento e pensamento $(3 \%)$

A TV faz ficar parado (1\%)
“Tipo aquelas propagandas pras pessoa mais gordinhas, fala: ah! emagreça em pouco tempo e compra aqueles remédios doidos, isso aí causa muito doença, tipo aquela bulimia [...] 0 próprio marketing puxa o produto pras pessoas comprar [...] A TV só faz diminuir a felicidade da jovem, cada vez menos satisfeita com o corpo dela [...] Todo mundo assim quer ficar como se fosse modelo e acaba assim discriminando as outras pessoas, chegando a humilhar [...]".

"A TV e a revista influencia muito e algumas pessoas são estimuladas e a gente acaba imitando coisas que aparecem nos filmes, novelas, propagandas mas depende da cabeça de cada um, da personalidade da pessoa [ ... ] vai de cada um $[\ldots] "$.

“Na TV, todo mundo é magro e não é bem assim na vida real [...] que aquilo ali na TV é tudo lipoaspiração e essas coisas não são saudáveis [...] eles não pegam tipo assim pessoa gordinhas, só com o corpo meio que preparado e isto acaba sendo uma ilusão [...] só que a pessoa acaba não percebendo que aquilo não é real, que é tudo um processo de maquiagem, câmara, luz que interfere, criando uma imagem do ser idealizado na televisão e isto não é legal".

"Passam muito o padrão de moda, da roupa, maquiagem, cabelo [...] todo mundo tem que ser magro, bonito e perfeito [...] a moda hoje é praticamente só pros magros [...] a mídia influenciou as pessoas a gostarem de pessoas magras, é como aquela modelo de corpo perfeito, as meninas acabam querendo ter as roupas [...]".

"M uito na TV, desses produtos pra emagrecer tal, afeta tipo mais as meninas [...] elas tentam alcançar aquilo que vêem na TV, com regime essas coisas assim, se preocupam muito com isso e às vezes acabam até se prejudicando [...]".

"A mídia coloca um negócio e você tem que seguir, né? Tem um estereótipo e as pessoas têm que seguir aquilo pra ser aceita, principalmente na parte visual de apresentação e as pessoas acham que tem que ser assim, se não tá fora do normal e até mesmo pode se sentir excluído.[...]".

“Por ser televisão, por estar todos os dias lá, a pessoa acaba assistindo, ficando vinculada e então cria assim um hábito e aquilo acaba entrando na cabeça da pessoa, que ela tem que ser igual àquilo [...] é como se fosse uma coisa que te controla, né? Vai até além, não fica só na parte física, tipo o gordo é nojento e preguiçoso e o atlético é fútil, acaba indo por toda extensão de pensamento e comportamento [...]".

"A televisão faz o jovem ficar parado às vezes muito tempo, aí pode não fazer exercício e ficar comendo, vendo televisão e traz uma série de problemas [...]". 
Tabela 2. Ideia central, frequência da resposta e o discurso do sujeito coletivo dos adolescentes, segundo conteúdos que identificaram uma relação positiva e uma relação positiva e negativa concomitantemente, entre a mídia e o corpo. São Bernardo do Campo, 2006.

\begin{tabular}{ll}
\hline \multicolumn{1}{c}{$\begin{array}{c}\text { I deia central } \\
\text { (frequência da resposta) }\end{array}$} & \multicolumn{1}{c}{ Trechos do discurso do sujeito coletivo } \\
\hline $\begin{array}{l}\text { Existe o lado positivo e } \\
\text { negativo (9\%) }\end{array}$ & "A TV passa coisas boas, tem alguma coisa que você vê e procura o médico, \\
& $\begin{array}{l}\text { no aspecto da pessoa querer se cuidar e tal, mostra bastante a realidade, só } \\
\text { que também tem coisas ruins, tipo aqueles remédios que passam, muito } \\
\text { perigoso pra emagrecer [...] isto prejudica bastante e tem gente que não } \\
\text { tem limite [...] A caba perdendo também a cultura e tendo vulgarização. A }\end{array}$ \\
& $\begin{array}{l}\text { gente se veste aqui igual lá nos Estados Unidos [...]". } \\
\text { A influência é positiva (9\%) }\end{array}$ \\
& $\begin{array}{l}\text { "A TV pode ser um bom instrumento de informação, passa muita coisa } \\
\text { boa, pra tentar conscientizar [...] fala de alimentação, trazem dietas, um } \\
\text { corpo mais forte. Tem muita gente preocupada com a sua forma física e a }\end{array}$ \\
\hline
\end{tabular}

Tabela 3. Ideia central, frequência da resposta e o discurso do sujeito coletivo dos adolescentes, segundo conteúdos que identificaram relação, sem julgamento de valor, entre a mídia e o corpo. São Bernardo do Campo, 2006.

\begin{tabular}{ll}
\hline \multicolumn{1}{c}{$\begin{array}{c}\text { I deia central } \\
\text { (frequência da resposta) }\end{array}$} & \multicolumn{1}{c}{ Trechos do discurso do sujeito coletivo } \\
$\begin{array}{l}\text { Existe relação entre a TV e o corpo } \\
\text { do jovem (9\%) }\end{array}$ & $\begin{array}{l}\text { "A mídia realmente faz uma imagem que todos os adolescentes, } \\
\text { qualquer tipo, gostaria de seguir. Tem bastante gente que acredita } \\
\text { nas revistas, nessas Herbalife da vida e na TV eles pegam as pessoas } \\
\text { mais em forma, né? E essas pessoas que trabalham em TV, jornais, as } \\
\text { mulheres são bem magras, sempre com bastante peito e bastante } \\
\text { bunda, sempre tipo assim, um padrão". }\end{array}$ \\
Existe, mas não sei explicar (3\%) & "Tem, mas não sei explicar [...]". \\
A Internet também influencia (1\%) & "A Internet influencia o jovem, até no corpo assim [...]". \\
\hline
\end{tabular}

Tabela 4. Ideia central, frequência da resposta e o discurso do sujeito coletivo dos adolescentes, segundo conteúdos que identificaram pouca ou nenhuma relação entre a mídia e o corpo. São Bernardo do Campo, 2006.

\begin{tabular}{|c|c|}
\hline $\begin{array}{l}\text { Ideia central } \\
\text { (frequência da resposta) }\end{array}$ & Trechos do discurso do sujeito coletivo \\
\hline Não influencia (5\%) & $\begin{array}{l}\text { “Cada um cuida do corpo do jeito que quer. Não tem nada a ver TV } \\
\text { com jovens, não existe nenhuma relação, não interfere em nada só } \\
\text { por tá vendo o programa”. }\end{array}$ \\
\hline Não influencia muito (1\%) & $\begin{array}{l}\text { "Não influencia muito, mas têm alguns adolescentes que entram na } \\
\text { academia e tal }[. . .] " .\end{array}$ \\
\hline
\end{tabular}

duzir esquemas dominantes de significação e interpretação do mundo. Nesta direção, "ser belo" e "ser magro" configura-se como um modelo de unidade propagado pelos meios de comunicação 
que produz formas de existir e se relacionar. Puderam ser observadas no discurso do sujeito coletivo estas fragmentações. Idéias centrais como "existe, mas depende de cada um" (8\%); "a TV engana, mostra uma coisa que não é" (5\%); “interfere ditando um padrão de moda" (4\%); "afeta mais as meninas" (4\%); "seguir estereótipos para ser aceito (4\%); "influencia no comportamento e pensamento" (3\%) ea "TV faz ficar parado" (1\%) foram registradas na construção do discurso coletivo que inferiu uma participação negativa da mídia e o corpo do jovem.

Foi possível registrar idéias centraisqueabordaram 0 aspecto positivo da mídia (9\%) e a influência positiva e negativa ao mesmo tempo (9\%). Fischer ${ }^{4}$ descreve o dispositivo pedagógico da mídia por meio de estratégias, nas quais a TV assume um lugar especial de educar, fazer justiça, promover a investigação dos fatos, indo até para os cuidados para com o próprio corpo. Pela construção do discurso do sujeito coletivo, verificouse este desdobramento na relação entre a tel evisão e o corpo, pela ótica do adolescente. Mas, ainda para a autora, faz-se necessário desvelar os conteúdos dos materiais televisivos para, assim, ter-se acesso aos conteúdos positivos provenientes dos programas da televisão. Deve-se ir além, apontando para a necessidade de se ampliar a compreensão acerca das formas concretas pelas quais o indivíduo é diariamente informado, os modos como as emoções são mobilizadas e as estratégias de construção de sentidos na TV, entre outros fatores.

Em pesquisa com crianças ${ }^{19}$, foram descritas e avaliadas as relações que as mesmas estabelecem com o que vêem na TV. Foi observado que, apesar das críticas que os adultos fazem à TV, as crianças têm grande consideração pela mesma, porque, na opinião delas, é possível aliar aprendizagem ao entretenimento, oferecendo a chance deter acesso aos conhecimentos de que precisam para ter um futuro agradável, atraente e interessante. N o DSC da presente pesquisa, foi registrado, em $9 \%$ das idéias centrais, esta influência, sendo confirmado neste fragmento: "pode ser um bom instrumento de informação, passa muita coisa boa, mostra o que tá acontecendo pra tentar conscientizar".

Fischer ${ }^{4}$ afirma que, consciente ou não, temse na TV, nas revistas de ampla divulgação, nos programas de rádio, um lugar de aprendizado a respeito do próprio indivíduo, da vida levada, da forma como se recebe e se avalia, pessoas classificadas como heróis ou vilões, cidadãos corretos ou transgressores da ordem. Fávaro et al. ${ }^{20}$ con- firmam esta tendência com pesquisa com pré adolescentes e a novela "M al hação". Registraram o predomínio do julgamento moral conservador dos personagens com a manutenção de papéis masculinos e femininos que privilegiam 0 status masculino.

Registrou-se $13 \%$ das idéas centrais que identificaram uma relação entre a TV e o corpo, mas sem um julgamento de valor. No discurso do sujeito coletivo, estavam presenteidéias como "existe relação entre a TV e o corpo, e"na TV eles pegam as pessoas mais em forma, né?", "existe, mas não sei explicar" "e "a internet também influencia".

Identificou-seainda, em $5 \%$ das idéias centrais, pouca ou nenhuma relação entre os temas pesquisados. No discurso do sujeito coletivo, estavam presentes idéias como "cada um cuida do corpo do jeito que quer e não tem nada a ver a TV com os jovens" e "não influencia muito, mas têm alguns adolescentes que entram na academia e tal".

Apesar da maioria da idéias centrais abordarem o conhecimento do jovem acerca do poder da mídia em relação ao seu corpo, este fato, isoladamente, parece não ser o suficiente para a aceitação do jovem em relação ao corpo. Pesquisas inferem que, independente da apresentação corporal, adolescentes são insatisfeitos com seu corpo ${ }^{21,22 .}$

Tendo-seo indivíduo, o seu psiquismo, como foco de atenção, a teoria psicanalítica se ocupa em decifrar os mistérios obscuros desta estrutura, ou seja, a alma humana. Como uma possibilidade interpretativa, $\mathrm{N}$ asio ${ }^{23}$ revela a ação e reação do indivíduo, explicando, entre tantos conceitos, o referente à "alienação no desejo do outro". Para o pesquisador, estar alienado é não ter uma unificação psíquica, é apresentar-se de forma incoordenada e, como uma saída para o indivíduo manter-se ativo, utiliza o recurso da alienação naquilo em que consegue se constituir. Ainda para o autor, se existe um "eu" (indivíduopsiquismo), este é resultado do efeito que o "outro" (seus pares e grupo social) tem sobre ele, ao preço da imagem criada acerca de si próprio ser constituída no "outro" e pelo "outro", ficando, assim, primordialmente alienada neste. $N$ este cenário, o desejo do indivíduo torna-se uma expressão do desejo do "outro". Nasio ${ }^{23}$ vai além, afirmando que o "eu" pouco ou quase nada sabe acerca de seu desejo, a não ser o que o "outro" o revela, de modo que o objeto de desejo do "eu" nada mais é do que o objeto de desejo do "outro".

Partindo-se deste referencial, as manobras aplicadas pela mídia são eficazes na manipulação do comportamento do adolescente, visto que 0 desejo do adolescente se expressa na medida em 
que se identifica com o desejo do "outro" que, no caso, poderiam ser as mensagens, idéias e imagens promovidas pela mídia. Sendo assim, é possível compreender os motivos pelos quais os jovens, mesmo cientes da interferência da mídia em relação ao corpo, pouco alteram suas atitudes em relação ao mesmo, pois, de acordo com a teoria psicanalítica, estão alienados no desejo do outro.

Seguindo esta linha deraciocínio, um dos principais objetos de desejo vendido pela mídia - o "outro" - seria a conduta de consumo, atrelando este comportamento às imagens de sucesso, realização e prazer. A postura hedonista do homem é explorada pelos profissionais de marketing, que sabem como ninguém vender uma idéia e/ou imagem e atrelá-las às realizações de desejos ${ }^{24}$.

Reis J $\mathrm{r}^{9}$ afirma que, sem se dominar os processos de construção de mensagens, dificilmente o jovem espectador poderá analisar criticamente os produtos à sua disposição ou ser menos influenciado por eles. Assim, o "belo" e a forma do jovem relacionar-se consigo próprio e com o seu meio social são padronizados e definidos pelos grandes meios de comunicação por meio dos programas e propagandas.

É importante sinalizar que as contradições sociais estão presentes nos discursos dos jovens, pois, se por um lado há uma cobrança de um corpo ideal, magro e esguio para as meninas e um corpo forte e musculoso para os meninos, por outro, observa-se no meio televisivo um estímulo ao consumo de alimentos calóricos ${ }^{3}, \mathrm{com}$ pouca prática esportiva e uso excessivo de TV, videogames e computadores.

Del Priori ${ }^{25}$, em análise acerca das transformações do corpo feminino no Brasil, pontua as interrelações entre as mudanças socioculturais e o cuidado da mulher destinado ao seu corpo. Sinaliza direções já desde o início do século passado, com a introdução e estímulo da prática desportiva para o combate do "ócio" e os "hábitos mundanos" da juventude, o lançamento de certos produtos de beleza que começavam a ser industrializados, a inovação dos saldos e liquidações que permitia às camadas urbanas médias adotar a roupa de gente rica. Desenhava-se paulatinamenteum padrão decomportamento ebeleza calcado na aparência física. A palavra de ordem tornava-se "bel eza" e toda feiúra deveria ser banida ${ }^{25}$.

A mídia televisiva e revistas apoderaram-se destes conceitos, tornando-os comuns à realidade cotidiana. N os discursos dos adolescentes, foi possível identificar estas relações. Para Gomes ${ }^{1}$, a subjetividade contemporânea está cunhada no consumo. Segundo a autora, nossas roupas, nossos acessórios, os objetos que usamos, tudo nos constitui como sujeitos identificados com a cultura que consumimos e nossa identidade é marcada por aquilo que podemos ou não podemos possuir e assim definir um lugar espeć́fico nas redes sociais. N esta mesma direção, $M$ oreir ${ }^{26}$ sinaliza que há tendências perigosas na participação da cultura midiática na formação da identidade de crianças e jovens, como, por exemplo, o esvanescimento da percepção dos limites entre o real e a ficção, a superexposição à imagem gerando a preguiça do pensamento, o desinteresse pela leitura, a incessante pedagogia da propaganda com a busca de uma formação de hábitos leais ao consumo em detrimento da autonomia e do senso crítico e, especialmente, o espelhamento narcísico, pela imersão no mundo virtual.

Uma das hipóteses para se compreender esta intrincada relação entre a mídia e a adolescência é sugerida por M oreira ${ }^{26}$, que pontua 0 quanto 0 sistema midiático-cultural, por intermédio da publicidade e propaganda, modula os comportamentos das crianças, até o ponto de serem julgados como naturais para a realidade cotidiana e até em relação à própria subjetividade. Sendo assim, crianças desde muito cedo aprendem a "Ier" o mundo, a "identificá-lo" e a "desejá-lo" muito antes de serem alfabetizadas, ou até antes mesmo de aprenderem a falar. Esse efeito é possível de ser observado nas atitudes eescolhas dos jovens de hoje, que como crianças em um passado recente, foram submetidas a este processo doutrinário de educação midiática. M esmo revelando ciência acerca do efeito da mídia em relação ao corpo, nos discursos dos jovens, foi possível observar que percebem suas atitudes como "normais", muitas vezes não avaliando de forma crítica esta interferência.

Outro ponto a ser discutido refere-se à percepção subliminar ${ }^{24}$, entendida como a influência exercida sobre a atitude ou comportamento por uma mensagem ou informação que não é percebida conscientemente, remetendo o indivíduo a camadas mais profundas do psiquismo. Segundo os profissionais da área, por uma questão ética, esta técnica de persuasão foi abandonada em favor da propaganda aberta e controlada. M esmo assim, o que se observa é a modulação dos comportamentos individuais e coletivos, tendo-se na mídia uma grande vitrine de exposição. No entanto, cabe reforçar que, se por um lado a mensagem publicitária que passa pela tela em velocidade rápida, de frações de segundos, não é mais aplicada, por outro lado, têm-se 
exposições às mensagens, como, por exemplo, em folhetos, fôlderes eaté em capas de revistas, e que talvez possam ser registrados em algum nível inconsciente ${ }^{24}$, modulando os comportamentos individuais e sociais.

Este tema é pivô de discussões recentes. M 0vimentos de categorias de classes profissionai ${ }^{27}$, bem como a mídia escrita ${ }^{28}$, mobilizam-se para sinalizar a importância de uma maior compreensão das relações entre a mídia, em especial a tel evisiva, eseus efeitos na formação das crianças e jovens. Estas entidades pontuam os excessos ocorridos nas programações, o que inclui os comerciais, no sentido de estimular crianças e jovens a adotar um padrão alimentar inadequado, sendo este mais um dosfatores responsáveis pela prevalência de doenças como o sobrepeso e a obesidade, definida atualmente como a grande epidemia do sécul o ${ }^{29}$. Em outro extremo, encontram-se as doenças como a anorexia e bulimia nervosas, associadas diretamente a um padrão máximo de magreza veiculado pela mídia ${ }^{30}$.
No sentido de superar o olhar reducionista sobre a questão da influência da TV sobre o jovem, desta ser positiva ou negativa, Gonçalves ${ }^{31}$ propõe um olhar abrangente, partindo-se do princípio que a TV na sociedade e na vida do jovem é um fato, sendo, portanto, necessário ser avaliada como tal, a fim de se apontar possibilidades ealternativas. A autora propõe um conhecimento dos elementos mediadores presentes no processo de constituição da consciência, oriundos e veiculados pela televisão.

Conclui-se que os jovens pesquisados revelaram ciência da relação entre a mídia e o corpo. Pais, educadores, pesquisadores e a sociedade civil devem atentar-se para a interferência da TV na formação do jovem. N esse sentido, os mesmos, além de outros profissionais, gestores da saúdee especial istas da mídia, devem secomprometer em conhecer mais aprofundadamente estas relações e propor medidas deintervenção que proporcionem a valorização dos aspectos positivos do uso da TV e coíba os negativos.

\section{Colaboradores}

Conti M A, Toral N ePeres SV participaram igualmente em todas as etapas do artigo. 


\section{Referências}

1. Gomes PBMB. Mídia, imaginário de consumo e educação. Educ. Soc. 2001; 74:191-207.

2. Setton M GJ. Família escola e mídia: um campo com novas configurações. Educação e Pesquisa 2002; 28(1):107-116.

3. Serra GMA, Santos EM. Saúde e mídia na construção da obesidade e do corpo perfeito. Cien Saude Colet 2003; 8(3):691-701.

4. Fischer RMB. O dispositivo pedagógico da mídia: modos de educar na (e pela) TV. Educ. Pesqui. 2002; 28(1):151-162.

5. Constantini A. Bullying: como combatêlo: prevenir e enfrentar a violência entre os jovens. São Paulo: Itália Nova Editora; 2004.

6. Tiggemann M, Gardiner M, Slater A. "I would rather be size 10 than have straight A's": A focus group study of adolescent girl's whish to be thinner. J Adolescence 2000; 23:645-659.

7. Fischer RMB. Mídia e juventude: experiências do público e do privado na cultura. Cad. Cedes 2000; 25(65):43-58.

8. Instituto Brasileiro de Geografia e Estatística. Pesquisa Nacional por Amostra de Domicílios. Rio de Janeiro: IBGE; 2006.

9. Reis Junior JAA. Decifra-me ou te devoro. Cad Cedes 2005; 25(65):59-70.

10. Pereira M G. Epidemiologia: teoria e prática. Rio de Janeiro: Guanabara Koogan; 1999.

11. M inayo M CS. 0 desafio do conhecimento: pesquisa qualitativa em saúde. 8a ed. São Paulo: Hucitec; Rio de Janeiro: Abrasco; 2004.

12. Flick U. Entrevistas episódicas. In: Bauer M W, Gaskell $\mathrm{G}$, organizadores. Pesquisa qualitativa com texto, imagem e som. Petrópolis: Vozes; 2002. p.114-136.

13. Lefèvre $A M C$, Lefèvre $F, C$ ardoso $M R L$, Mazza M M PR. Assistência pública à saúde no Brasil: estudo de seis ancoragens. Saude Soc. 2002; 11:35- 47.

14. Jodelet $D$. Representação social: um domínio em expansão. In: Jodelet $D$. As representações sociais. São Paulo: EDUC; 2002.

15. Lefèvre $F$, Lefèvre $A M C$. Os novos instrumentos no contexto da pesquisa qualitativa. In: Lefèvre $F$, Lefèvre AMC, Teixeira JJV, organizadores. 0 discurso do sujeito coletivo: uma nova abordagem metodológica em pesquisa qualitativa. Caxias do Sul: EDUCS; 2000. p. 11-35.

16. Edlund B, Sjodén PO, Gebre-M edhin M. Anthropometry, body composition and body image in diet and non-dieting 8-16 years old Swedish girls. Acta Pediatrics 1999; 88:537-544.

17. Sherwood NE, Newmark-Sztainer D. Internalization of the sociocultural ideal: weight-related attitudes and dieting behavior among young adolescent's girls. Am J H ealth Promot 2001; 15(4):228-231.
18. Coimbra CM B. Mídia e produção de modos de existência. Psic.: Teor. e Pesq. 2001; 17(1):1-4.

19. Duarte R, Leite C, M igliora R. Crianças e televisão: o que elas pensam sobre o que aprendem com a tevê. Rev. Bras. Educ. 2006; 11(33):497-564.

20. Fávaro MH, Abrão LGM. "Malhando o gênero": o grupo focal e os atos da fala na interação de adolescente com a telenovela. Psic.: Teor. e Pesq. 2006; 22(2):175-182.

21. Gittelsohn J, Harris SB, Thorne-Lyman AL, Hanley AJB, Barnie A, Zinman B. Body image concepts differ by age and sex in a Ojibway-Cree community in Canada. J Nutr. 1996; 126(12):2990-3000.

22. M cCabe M, Ricciardelli L. Parents, peers and media influence on body image and strategies to both increase an decrease body image size among adolescents boy and girls. Adolescence 2001; 36(12):226-240.

23. Nasio JD. Introdução às obras de Freud, Ferenczi, Groddeck, Klein, Winnicott, D olto, Lacan. Transmissão da Psicanálise - 41. Rio de Janeiro: Jorge Zahar; 1995.

24. Gade C. Psicologia do consumidor e da propaganda. São Paulo: EPU; 1998.

25. Del Priore M. Corpo a corpo com a mulher: pequena história das transformações do corpo feminino no Brasil. São Paulo: Senac; 2000.

26. M oreira AS. Cultura midiática e educação infantil. Educ. Soc. 2003; 24(85):1203-1235.

27. Conselho Federal de Psicologia. [site da Internet]. [acessado 2007 junho 14]. Disponível em: http//: www.pol.org.br/midia

28. Tavares F, Greenhalgh L, Doria P. Moralismo ou proteção às crianças. 0 Estado de São Paulo 2007; 18 fev.

29. Word Health Organization. O besity: Prevent and managing the global epidemic. Geneva: WHO; 2000.

30. Keery H, Beg PVD, Thompson JK. An evaluation of the tripartite influence model of body dissatisfaction and eating disturbance with adolescent girls. Body Image 2004; 1(3)237-251.

31. Gonçalves M GM. Concepções de adolescência veiculadas pela mídia televisiva: um estudo das produções dirigidas aos jovens. In: Ozella S. Adolescências construídas. São Paulo: Cortez; 2003.

Artigo apresentado em 03/01/2008

Aprovado em 12/03/2008

Versão final apresentada em 14/04/2008 